\title{
Prevalence of Menstrual Distress among Young Undergraduate Females in Quetta Balochistan
}

\section{Tabassum Khan $\mathrm{N}^{*}$ and Jameel $\mathbf{N}$}

Department of Biotechnology, Balochistan University of Information Technology Engineering and Management Sciences (BUITEMS), Pakistan

*Corresponding author: Nida Tabassum Khan, Department of Biotechnology, Faculty of Life Sciences and Informatics, Balochistan University of Information Technology Engineering and Management Sciences, (BUITEMS), Quetta, Pakistan, Tel: 03368164903; Email: nidatabassmkhan@yahoo.com

\section{Research Article}

Volume 4 Issue 1

Received Date: January 11, 2020

Published Date: January 28, 2020

DOI: $10.23880 /$ eij-16000136

\section{Abstract}

Menstrual related issues poses substantial health implications in young women who faces problems such as misses their school, not be able to participate in activities, struggle to carry out their usual daily activities, feel uncomfortable around people etc. In addition symptoms like cramps, tiredness, back pain, swollen abdomen, and tender breasts were reported in women suffering from menstrual distress leading to damaging effects on their psychological and reproductive health. Therefore the aim of this study was to determine the prevalence of menstrual issues among young females and also to identify those factors that contributes in causing such a distress. Our obtained results suggested high prevalence of menstrual distress as $47 \%$ of undergraduate females were suffering from menstruation distress of different kinds due to high stress, poor health etc.

Keywords: Psychological Stress; Amenorrhea; Oligomenorrhea; Hormone; Anorexia Nervosa

\section{Introduction}

A menstrual related issue poses substantial health implications in young women [1]. Menstrual related problems among young females causes them to be absent from their work and school along with poor psychosocial and mental development [2,3]. In adults, factors like depression and anxiety have an impact on women menstrual cycles [4]. In addition symptoms like cramps, fatigue, backache, swollen abdomen, and tender breasts were reported in women suffering from menstrual distress [5,6]. Research revealed that these menstrual distress affects their daily activities as well as their reproductive and psychological health $[7,8]$. Menstrual cycles is mostly accompanied by a number of painful symptoms such as premenstrual syndrome in which symptoms like mild cramping and fatigue occurs [1]. However the severity of these symptoms varies from female to female depending on their health, diet, living style and other factors [9]. Smoking, alcohol consumption, gain of appetite were also some factors reported among women with menstrual-related problems [10,11]. Besides, young women also suffers from disturbed emotional feelings such as sadness, restlessness, desperation etc $[12,13]$. If there is an absence of a cycle or an abnormal or light bleeding, it is an indication of abnormal menstrual cycle. Therefore it is essential to stay in touch with a gynecologist to identify any significant variations in a regular menstrual cycle [14]. The main aim of this study was to find out the prevalence of menstrual distress faced by young undergraduates and to find out those factors responsible for causing it.

\section{Methodology}

This research was a cross-sectional survey based study, 
conducted among the female undergraduate students studying in different educational institutions of Quetta, Balochistan. The sample sizes were kept 100 and students were selected at random. Married undergraduate females were excluded from this study. Study was carried out with the help of a questionnaire designed to find out the prevalence of different menstrual problems among young females Data was statistically analyzed using Microsoft excel 2013.

\section{Results}

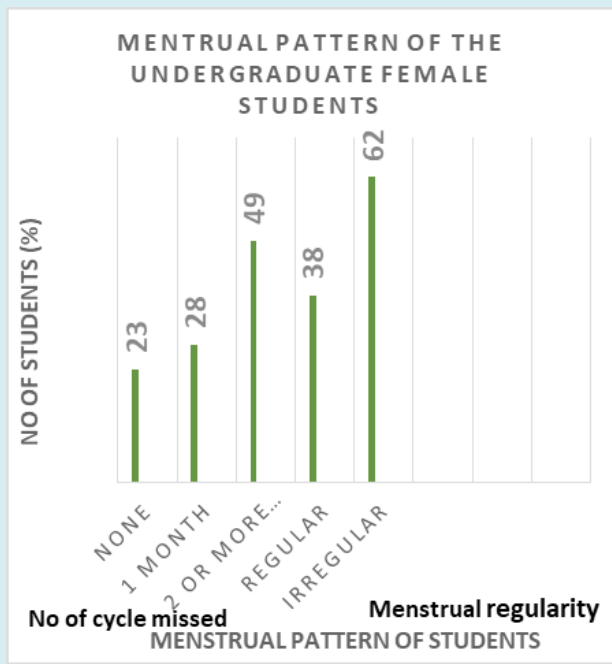

Graph 1: Menstrual pattern of the undergraduate female students.

Graph 1 depicts the menstrual pattern of the adolescent undergraduate females including number of cycle and menstrual regularity.

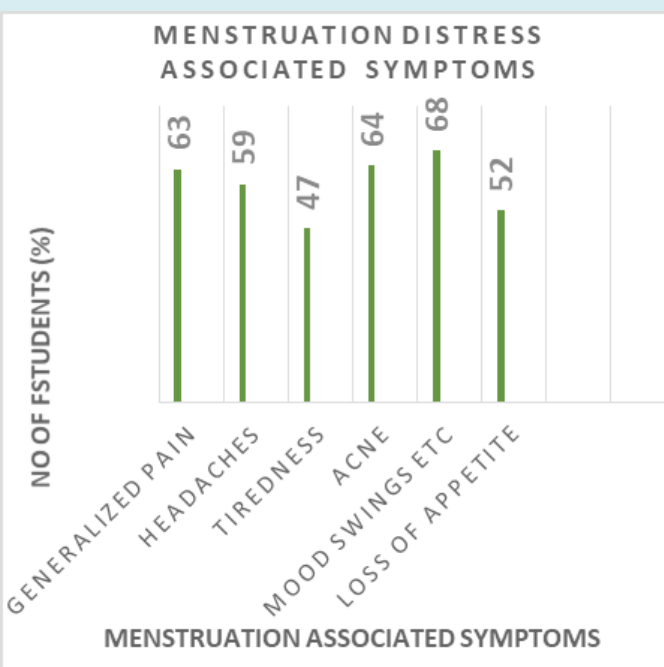

Graph 2: Menstrual associated symptoms suffered by the undergraduate female students.
Graph 2 depicts the different menstruation distress associated symptoms suffered by the undergraduate female students.

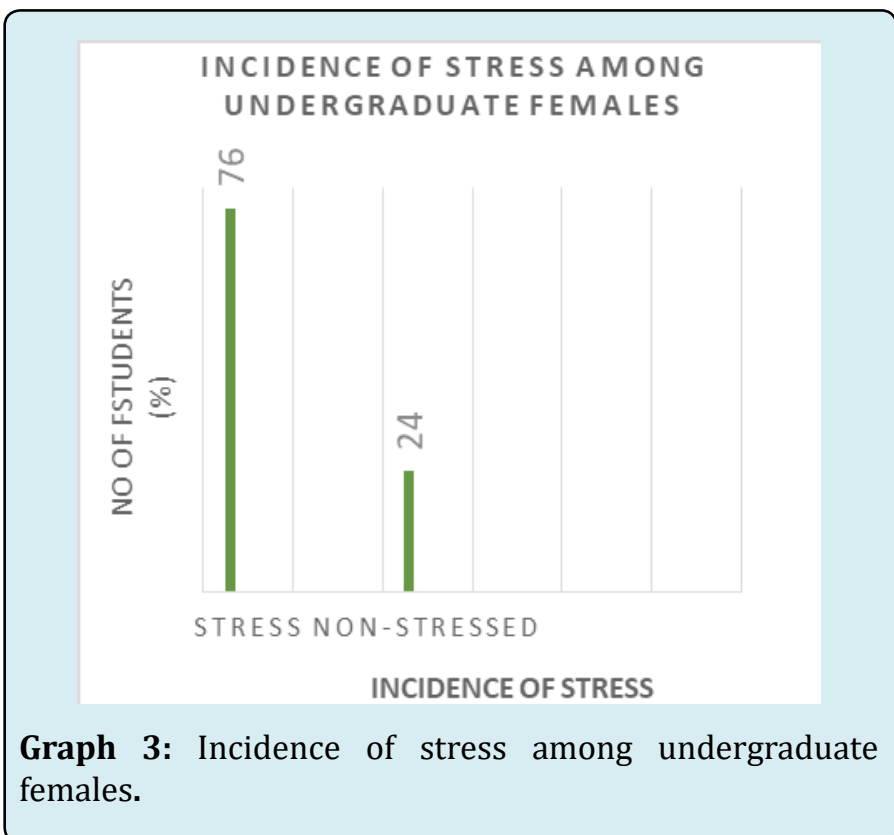

Prevalence of stress among 100 adolescent undergraduate female students were given in Graph 3.

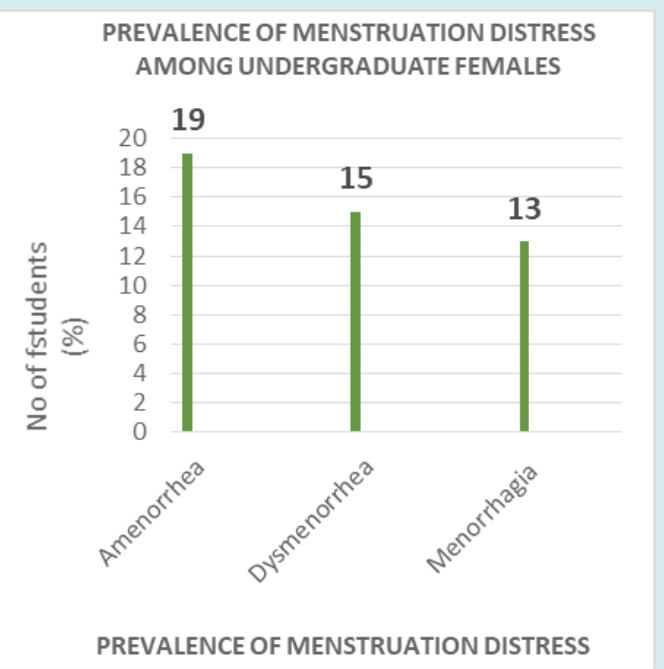

Graph 4: Prevalence of Menstruation distress among undergraduate females.

Prevalence of menstruation distress among 100 adolescent undergraduate female students were given Graph 4. 


\section{Epidemiology International Journal}

\section{Discussion}

Menstruation distress can affect your quality of life especially young undergraduate females who misses their school, not be able to participate in activities, struggle to carry out their usual daily activities, feel uncomfortable around people etc $[15,16]$. As our obtained results suggested that the prevalence of menstruation distress among young undergraduates is high as out of 100 sample size 19\% suffered from amenorrhea (absence of menstruation for 2 or more months), $15 \%$ dysmenorrhea (painful periods) and $13 \%$ menorrhagia (heavy bleeding) (graph 4).So a total of 47 female undergraduates out of 100 suffers from menstruation distress of different kinds keeping in mind that approximately $62 \%$ females were having irregular menstruation cycles out of 100 as depicted in graph 1.Amenorrhea and dysmenorrhea is the most prevalent type of menstruation distress among young females due to poor diet, low body weight and malnourishment [17,18]. These conditions may lead to poor psychological health and weak reproductive health with severe consequences in the adulthood $[19,20]$. Stress is also one of the most important contributing factor in causing menstruation distress among undergraduate females as graph 3 depicted that $76 \%$ of females were under high stress mainly due to their studies, work load, gpa concern and other associated factors [21]. This stress might also come from their home environment and their surroundings [22]. The remaining proportion of young females having irregular menstruation cycle may be due to genetic factors or might be due to some serious medical illness that was not taken in account in this study. These menstruation related problems among undergraduate females were also accompanied by symptoms including headache, generalized pain, acne, mood swings etc [23] thus increasing the severity of these distresses to a point where it starts to affect their daily routine (graph 2). Therefore it is potent to keep in check their menstruation cycle to avoid such distress. However there were certain limitations in this study such as family history of the female students were not taken into account and physical examination of the females should be done for better understanding of such a medical condition. The results of this study may provide a useful reference for designing menstrual health programs for adolescents at BUITEMS

\section{Conclusion}

Thus early documentation of menstrual associated problems in young females is required as these distresses affects the academic performance of the female students. In addition also exhibits damaging effects on their psychological and reproductive health. Such female students should be provided with psychological and gynecological counselling, as well as advices and strategies for preventing future complications.

\section{References}

1. Beausang CC, Razor AG (2000) Young Western women's experiences of menarche and menstruation. Health Care for Women Int 21(6): 517-528.

2. Strine TW, Chapman DP, Ahluwalia IB (2005) Menstrualrelated problems and psychological distress among women in the United States. J Womens Health (Larchmt) 14(4): 316-323.

3. Cakir M, Mungan I, Karakas T, Girisken I, Okten A (2007) Menstrual pattern and common menstrual disorders among university students in Turkey. Pediatr Int 49(6): 938-942.

4. Tangen T, Mykletun A (2008) Depression and anxiety through the climacteric period: an epidemiological study (HUNT-II). J Psychosom Obstet \& Gynecol 29(2): 125131.

5. Dickerson LM, Mazyck PJ, Hunter MH (2003) Premenstrual syndrome. Am Fam Physician 67(8): 1743-1752.

6. Greene R, Dalton K (1953) The premenstrual syndrome. Br Med J 1(4818): 1007.

7. Friberg, B, Kristin Örnö A, Lindgren A, Lethagen S (2006) Bleeding disorders among young women: a populationbased prevalence study. Acta obstet Gynecol Scand 85(2): 200-206.

8. POUR EM, OUSATI AF (2002) Attitudes of female adolescents about dysmenorrhea and menstrual hygiene in Tehran suburbs.

9. Jarrah SS, Kamel AA (2012) Attitudes and practices of school-aged girls towards menstruation. Int J of Nurs Pract 18(3): 308-315.

10. Peacock A, Alvi NS, Mushtaq T (2012) Period problems: disorders of menstruation in adolescents. Archives of disease in childhood 97(6): 554-560.

11. Russell GF (1972) Psychological and nutritional factors in disturbances of menstrual function and ovulation. Postgrad Med J 48(555): 10.

12. Steiner M, Streiner DL, Steinberg S, Stewart D, Carter D, et al. (1999) The measurement of premenstrual mood symptoms. J Affect Disord 53(3): 269-273.

13. May RR (1976) Mood shifts and the menstrual cycle. J Psychosom Research 20(2): 125-130. 


\section{Epidemiology International Journal}

14. Ivey ME, Bardwick JM (1968) Patterns of affective fluctuation in the menstrual cycle. Psychosom Med 30(3): 336-345.

15. Moos RH (1968) The development of a menstrual distress questionnaire. Psychosomatic medicine 30(6): 853-867.

16. Alonso C, Coe CL (2001) Disruptions of social relationships accentuate the association between emotional distress and menstrual pain in young women. Health Psychol 20(6): 411.

17. MEZER, J (1949) Traumatic amenorrhea with dysmenorrhea. J Am Med Assoc 141(9): 602-603.

18. Bachmann GA, Kemmann E (1982) Prevalence of oligomenorrhea and amenorrhea in a college population. Am J Obstet Gynecol 144(1): 98-102.

19. Harlow SD, Campbell OM (2004) Epidemiology of menstrual disorders in developing countries: a systematic review. BJOG 111(1): 6-16.

20. Stanton AL, Lobel M, Sears S, DeLuca RS (2002) Psychosocial aspects of selected issues in women's reproductive health: Current status and future directions. J Consult Clin Psychol 70(3): 751.

21. Sommer B (1978) Stress and menstrual distress. J Human Stress 4(3): 5-10, 41-47.

22. Barrow GW, Saha S (1988) Menstrual irregularity and stress fractures in collegiate female distance runners. Am J Sports Med 16(3): 209-216.

23. Yamamoto K, Okazaki A, Sakamoto Y, Funatsu M (2009) The relationship between premenstrual symptoms, menstrual pain, irregular menstrual cycles, and psychosocial stress among Japanese college students. J Physiol Anthropol 28(3): 129-136. 